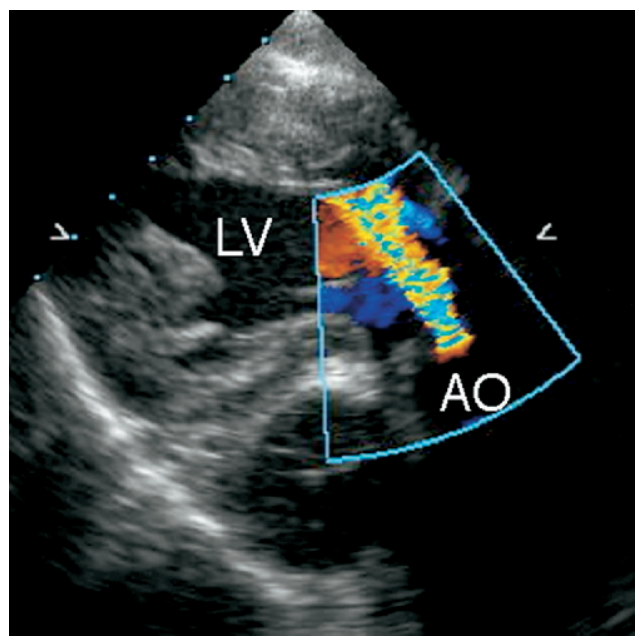

Figure 2. Transgastric echocardiographic long-axis view of the aortic valve. Color flow Doppler imaging reveals moderate aortic regurgitation. Detailed imaging of the aortic valve revealed fibrosed leaflets, leading to lack of central coaptation as the mechanism of the regurgitation. $L V$, Left ventricle; $A O$, aorta.

\section{References}

1. Novacek G, Haumer M, Schima W, Muller C, Miehsler W, Polterauer $\mathrm{P}$, et al. Aortic mural thrombi in patients with inflammatory bowel disease; report of two cases and review of the literature. Inflamm Bowel Dis. 2004;10:430-5.

2. Ozsoyler I, Yilik L, Bozok S, Ozbek C, Gurbuz A. Cardiovascular involvement in Crohn's disease in the absence of ankylosing spondylitis. Heart Vessels. 2005;20:164-6.

3. Pepper C, Munsch C, Sivananthan UM, Pye M. Unruptured aneurysm of the left sinus of Valsalva extending into the left ventricular outflow tract: presentation and imaging. Heart. 1998;80:190-3.

4. Biagi P, Castro R, Campanella G, Parisi G, Gobbini AR, Vedovini G. Takayasu's arteritis and Crohn's disease: an unusual association. Report on two cases. Dig Liver Dis. 2001;33:487-91.

5. Kanemitsu S, Shimono T, Kusagawa H, Onoda K, Yada I. Successful surgical treatment of Takayasu's arteritis associated with pyoderma gangrensoum. Ann Thorac Surg. 2005;80:1914-6.

\title{
The longest functioning heart valve prosthesis?
}

\section{Stephen Westaby, MD, PhD, ${ }^{a}$ Lognathen Balacumaraswami, FRCSEd FRCS(CTh), ${ }^{a}$ Nikant Sabharwal, MD, ${ }^{\text {b }}$ and} Harald Becher, MD, ${ }^{b}$ Oxford, United Kingdom

\section{Clinical Summary}

$\mathrm{I}$ n 1965, the Starr-Edwards silastic ball valve was the only commercially available heart valve prosthesis in Europe. ${ }^{1}$ We present the case of a 32-year-old man who was referred to the Hammersmith hospital that year with a severely regurgitant bicuspid aortic valve and heart failure. Before his operation, the heart-lung machine pioneer Dennis Melrose expressed concern that the Hammersmith system had not previously supported such a large patient $(190 \mathrm{~cm}, 98.5 \mathrm{~kg})$. During the opera-

From the Departments of Cardiac Surgery ${ }^{\mathrm{a}}$ and Cardiology, ${ }^{\mathrm{b}}$ John Radcliffe Hospital, Oxford, United Kingdom.

Received for publication May 4, 2007; accepted for publication May 30, 2007.

Address for reprints: Stephen Westaby, PhD, MS, FRCS, FETCS, FESC, FACC, FICA, Department of Cardiac Surgery, John Radcliffe Hospital, Headington, Oxford OX3 9DU, United Kingdom (E-mail: swestaby@ ahf.org.uk).

J Thorac Cardiovasc Surg 2007;134:1049-50

$0022-5223 / \$ 32.00$

Copyright $\odot 2007$ by The American Association for Thoracic Surgery doi:10.1016/j.jtcvs.2007.05.051 tion, the patient vividly recalls his surgeon, Professor Hugh Bentall, saying "Give it to him again," followed by 3 further shocks from the defibrillator! Eventually, the heart-lung machine and valve prosthesis proved more successful than the anesthetic, and the patient survived.

Consistent with the natural history of bicuspid aortic valves, the patient presented again in 2006 with central chest pain and an enormous ascending aortic aneurysm. ${ }^{2} \mathrm{~A}$ computed tomographic scan suggested a chronic DeBakey type II dissection (Figure 1). Transesophageal echocardiographic scanning showed a functioning ball valve prosthesis with a peak gradient of $24 \mathrm{~mm} \mathrm{Hg}$ and well-preserved left ventricular function. Both investigations indicated that the aneurysm was adherent to the posterior sternal table.

During femorofemoral cardiopulmonary bypass with profound hypothermia $\left(18^{\circ} \mathrm{C}\right)$, the sternal saw opened the aneurysm widely. Circulatory arrest was used to replace the ascending aorta and remodel the aortic root around the prosthesis and coronary ostia. The slightly discolored silicone ball remained spherical without a propensity to dislocate from the stainless-steel cage. It was retained to simplify the procedure and reduce operative time.

In 2007, the patient, the prosthesis, and the original surgeon (now aged 86 years) are in good condition. Repeat echocardiographic scanning shows a morphologically normal aortic root and ascending aorta. 


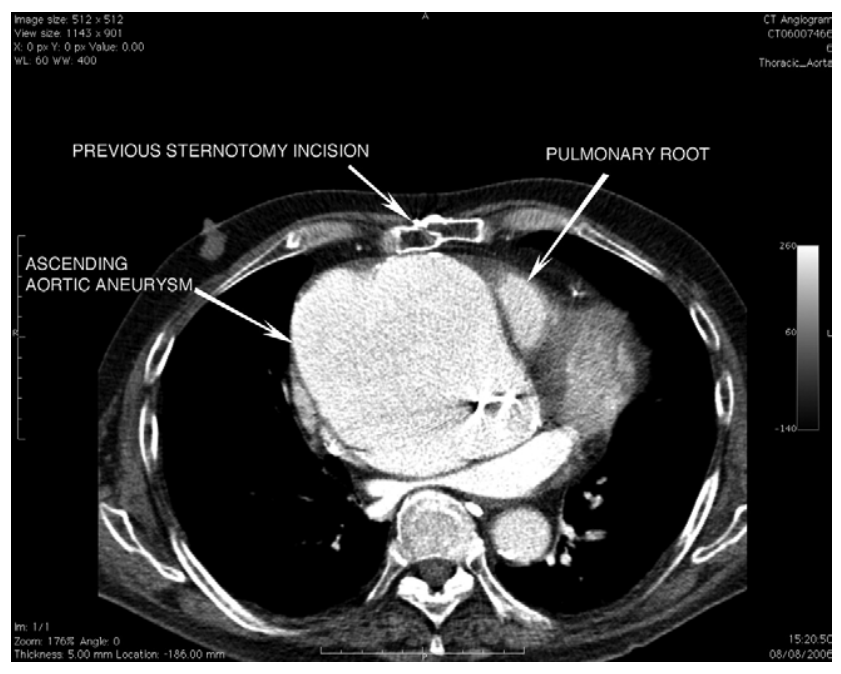

Figure 1. A computed tomographic scan showing the $15-\mathrm{cm}$ ascending aortic aneurysm containing a dissection flap and adherent to the posterior sternal table.

\section{Discussion}

The bicuspid aortic valve is the most common congenital lesion in adults and is often associated with ascending aortic and aortic root dilatation. In particular, progressive aortic dilatation results in dissection, underscoring the need for monitoring to facilitate prompt intervention. In our case a large false aneurysm that followed a chronic ascending aortic dissection had progressively expanded to adhere to the posterior sternal table. Hence, a preemptive surgical strategy with femorofemoral bypass was used to minimize the potential hazards of sternal reentry.

From the literature, the oldest functioning valve prosthesis to date was a 37-year-old Starr-Edwards valve replaced in 2003 for endocarditis. ${ }^{3}$ This valve was also structurally sound, but 17 years after the initial procedure, the patient experienced a cerebrovascular event. The international normalized ratio of 2.5 at that time reflected inadequate anticoagulation for this type of valve.

Our case is remarkable for 3 reasons. First, the patient is still in New York Heart Association class I after presentation with heart failure in 1965. Second, this first-generation heart valve has provided event-free survival for 42 years. Edwards Laboratories have confirmed this to be their longest functioning prosthesis. Lastly, anticoagulation with an international normalized ratio of between 3.5 and 4.5 has continued without bleeding or thromboembolic complications since 1965 . This is reassuring for all valve prosthesis patients who are prescribed this medication.

Stephen Westaby was Hugh Bentall's last chief resident at the Hammersmith Hospital in 1985. Albert Starr is now 80 years old.

\section{References}

1. Westaby S, Bosher C. Development of surgery for valvular hear disease. In: Westaby S, Bosher C, eds. Landmarks in cardiac surgery. Oxford: ISIS Medical Media; 1997.

2. Fedak PW, de Sa MP, Verma S, Nili N, Kazemian P, Butany J, et al. Vascular matrix remodeling in patients with bicuspid aortic valve malformations: implications for aortic dilatation. J Thorac Cardiovasc Surg. 2003;126:797-806.

3. Ozkokeli M, Ates M, Ekinci A, Akcar M. Thirty seven year durability of a Starr Edwards aortic prosthesis. Tex Heart Inst J. 2005;32:99-101. 